\title{
ENHANCED IN VITRO BIOLOGICAL ACTIVITY GENERATED BY SURFACE CHARACTERISTICS OF ANODICALLY OXIDIZED TITANIUM - THE CONTRIBUTION OF THE OXIDATION EFFECT
}

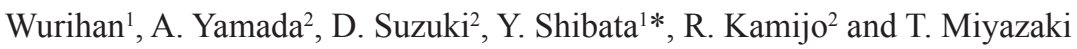 \\ ${ }^{1}$ Department of Conservative Dentistry, Division of Biomaterials \& Engineering, \\ Showa University School of Dentistry, Tokyo, Japan \\ ${ }^{2}$ Department of Biochemistry, Showa University School of Dentistry, Tokyo, Japan
}

\begin{abstract}
Anodically oxidized titanium surfaces, prepared by spark discharge, have micro-submicron surface topography and nano-scale surface chemistry, such as hydrophilic functional groups or hydroxyl radicals in parallel. The complexity of the surface characteristics makes it difficult to draw a clear conclusion as to which surface characteristic, of anodically oxidized titanium, is critical in each biological event. This study examined the in vitro biological changes, induced by various surface characteristics of anodically oxidized titanium with, or without, release of hydroxyl radicals onto the surface. Anodically oxidized titanium enhanced the expression of genes associated with differentiating osteoblasts and increased the degree of matrix mineralization by these cells in vitro. The phenotypes of cells on the anodically oxidized titanium were the same with, or without, release of hydroxyl radicals. However, the nanomechanical properties of this in vitro mineralized tissue were significantly enhanced on surfaces, with release of hydroxyl radicals by oxidation effects. In addition, the mineralized tissue, produced in the presence of bone morphogenetic protein-2 on bare titanium, had significantly weaker nanomechanical properties, despite there being higher osteogenic gene expression levels. We show that enhanced osteogenic cell differentiation on modified titanium is not a sufficient indicator of enhanced in vitro mineralization. This is based on the inferior mechanical properties of mineralized tissues, without either being cultured on a titanium surface with release of hydroxyl radicals, or being supplemented with lysyl oxidase family members.
\end{abstract}

Keywords: Titanium, hydroxyl radical, osteoblast, gene expression, nanoindentation.

*Address for correspondence:

Yo Shibata

Department of Conservative Dentistry,

Division of Biomaterials \& Engineering

1-5-8 Hatanodai, Shinagawa-ku, Tokyo 142-8555, Japan

Telephone number: +81337848178

Fax number: +81337848179

E-mail: yookun@dent.showa-u.ac.jp

\section{Introduction}

It is important to consider surface characteristics when designing titanium implants that generate new bone tissue and, consequently, osseointegration. Both surface topography and surface chemistry have been defined as important determinants toward the success of titanium implants (Boyan et al., 1996; Diebold, 2003; Jones et al., 2000; Shibata et al., 2002; Zhao et al., 2011). Anodically oxidized titanium enables micro-submicron topography during spark discharge. Functional groups also occur on the surface because surface anatase phase $\mathrm{TiO}_{2}$ in an amorphous matrix generates reactive oxygen species (ROS) such as $\bullet \mathrm{OH}$, generating hydrophilic functional groups when $\bullet \mathrm{OH}$ contacts water (Rajagopal et al., 2006; Shibata et al., 2010; Tizazu et al., 2009). Despite the efficacy of anodic oxidation in modifying titanium implants, the mechanism remains largely unexplored. This is mainly because the complexity of the surface characteristics makes it difficult to draw a consensus conclusion as to whether, or what extent, the surface characteristics of anodically oxidized titanium influence the biological activity. Studies have shown that osteoblasts cultured on the surface of anodically oxidized titanium (prepared by discharge in electrolytes) show increased expression of osteogenic genes and the extent of mineralized areas with harder and stiffer mechanical properties (Jang et al., 2014; Omori et al., 2009; Shibata et al., 2010). Such enhanced mechanical properties of the mineralized tissues are assumed as a function of $\bullet \mathrm{OH}$. The stored oxidation effects of $\bullet \mathrm{OH}$ may oxidize lysine residues of immature collagen molecules generated by osteoblasts, allowing collagen matrix crosslinking to be finalized, They also activate the biological function of oxidation enzymes, such as lysyl oxidase (LOX) family members (Shibata et al., 2013). However, the effect of the underlying $\bullet \mathrm{OH}$ has yet to be fully explained because of the difficulty of isolating the process of $\bullet \mathrm{OH}$ generation from the anodically oxidized titanium surface. - OH generation on the anodically oxidized titanium surface is mostly based on the anatase $\mathrm{TiO}_{2}$ phase in the amorphous matrix (Shibata et al., 2010). We therefore speculated that crystallization of the amorphous $\mathrm{TiO}_{2}$ matrix would enable a substantial reduction of the surface $\bullet \mathrm{OH}$ so that we could explore the pure role of $\bullet \mathrm{OH}$ generation on adherent cells.

In this context, we first performed surface characterization with $\bullet \mathrm{OH}$ detection of anodically oxidized titanium surfaces with, or without, additional thermal 
oxidation. Such thermal treatment has been used to identify the $\mathrm{TiO}_{2}$ crystal phase by X-ray diffraction, as thermal processing facilitates crystallization so that anatase or rutile crystal phases are more readily detectable (Takemoto et al., 2004). Subsequently, in vitro biological activity of primary osteoblasts on these anodically oxidized titanium samples, with or without $\bullet \mathrm{OH}$ release, was examined. This study investigated the enhanced nanomechanical properties of in vitro mineralized tissues, nearly independent of the gene expression patterns of osteogenic differentiation. Thus, comprehensive gene expression profiles on titanium samples were observed by DNA micro-array followed by real-time quantitative PCR.

In addition to the essential matrix protein expression associated with osteogenic cell differentiation on titanium implants, enhanced cross-linking in the matrix proteins should be an essential prerequisite in intact mineralized tissue with enhanced mechanical properties. This is based on the consideration that bone-like mineralized tissues such as bone and dentine are natural biocomposites.

Bone morphogenetic protein-2 (BMP2), one of the most commonly used anabolic agents in bone-repair strategies, substantially increases bone volume related to enhanced osteoblast differentiation (Chen et al., 2004; Gong et al., 2001; Mundy et al., 1999). The enhanced matrix protein generation associated with osteogenic cell differentiation by means of BMP2 is a widely accepted concept, even though BMP2 also diminishes the gene expression of LOX family members (Shibata et al., 2013). Therefore, mineralized tissues cultured with BMP2 and LOX-like 2 (LOXL2) on titanium plates were also assessed using nanomechanical testing. Given these observations in the present study, useful data could be gathered by comparing the oxidation effects between $\cdot \mathrm{OH}$ or LOX family members with osteogenic cell differentiation on titanium surfaces.

We postulate that the function of osteogenic cell differentiation alone on modified titanium surfaces, without proper collagen matrix maturation associated with $\bullet \mathrm{OH}$ or oxidation enzymes such as LOXL2, would not be sufficient to allow enhanced mineralization at the interface between the material surface and the host tissue.

\section{Materials and Methods}

\section{Specimen preparation}

JIS grade-2 titanium (KS-50, Kobe Steel, Tokyo, Japan) was used to prepare specimens as $10 \times 10 \times 1.0 \mathrm{~mm}$ plates and $8.0 \mathrm{~mm}$ diameter $\times 1.0 \mathrm{~mm}$ thickness discs for X-ray photoelectron spectroscopy (XPS ; ESCA-3400, Shimadzu, Kyoto, Japan). Each specimen surface was mechanically polished using waterproof polishing papers to \# 1200 under running water and then finished with alumina particles of $0.3 \mu \mathrm{m}$ diameter. Specimens were ultrasonically cleaned in acetone, detergent solutions (7X, ICN Biomedicals, Aurora, OH, USA) and pure distilled water each for $15 \mathrm{~min}$ (Ti specimens).

We prepared four types of specimens: Ti, Ho-Ti, Ao-Ti and Ao-Heat. To prepare Ho-Ti samples, Ti specimens were oxidized by heating at $600^{\circ} \mathrm{C}$ for $30 \mathrm{~min}$ in a dental furnace. To prepare Ao-Ti samples, Ti specimens were connected to the anode of a device developed in our research group and immersed in electrolytes. A $50 \times 100 \times 0.1 \mathrm{~mm}$ stainlesssteel plate was used as the counter-electrode. Discharge $\left(416 \mathrm{~mA} / \mathrm{cm}^{2}\right)$ was generated between the electrolyte and the working electrode through a gas layer on the surface of the electrode for $60 \mathrm{~s}$. Specimens were anodically oxidized in $100 \mathrm{~mL}$ of $1 \mathrm{M} \mathrm{Na}_{2} \mathrm{HPO}_{4}$. After this process, Ao-Ti samples were washed in pure distilled water. To prepare Ao-Heat samples, Ao-Ti specimens were heated at $600{ }^{\circ} \mathrm{C}$ for $3 \mathrm{~h}$ in a dental furnace. Through this post-thermal treatment, we anticipated that $\bullet \mathrm{OH}$ generation would be prevented on the surface of Ao-Heat samples so that we could then investigate the isolated effects of $\bullet \mathrm{OH}$ generated on the surface by comparing Ao-Ti and Ao-Heat. All of the titanium samples were dried and stored in a sealed desiccator for $24 \mathrm{~h}$.

\section{Surface characterization}

\section{Thin-film X-ray diffraction (TF-XRD)}

Prior to analysis, the crystal phases of the titanium samples were detected by TF-XRD (XRD-6100, Shimadzu) with $\mathrm{CuK} \alpha$ radiation. Pure rutile and anatase $\mathrm{TiO}_{2}$ (Wako Pure Chemical Industries Ltd., Osaka, Japan) were used for the standard reference materials. XRD was performed at $40 \mathrm{kV}$ and $40 \mathrm{~mA}$ with a scanning speed of $0.02^{\circ} / 4 \mathrm{~s}$ and a scanning range of $20-60^{\circ}\left(\theta=0.5^{\circ}\right)$.

\section{ROS detection on titanium surfaces by XPS}

As suggested by previous studies (Shibata et al., 2010; Takemoto et al., 2004), the generation of $\bullet \mathrm{OH}$ was detectable by XPS. The O1s binding energy originating from $\mathrm{TiO}_{2}$ is stable even after the oxidation process, whereas the Ti2p binding energy is more variable depending on the processing. Variations in the O1s spectra reveal the adsorption of oxidation products onto a titanium surface after treatment rather than titanium oxide films. Takemoto et al. (2004) reported the detection of $\bullet \mathrm{OH}$ using standard electron-spin resonance concomitant with the growth of the O1s peak around 531.0-532.0 eV on titanium exposed to $\mathrm{H}_{2} \mathrm{O}_{2}$. Therefore, we evaluated the - $\mathrm{OH}$ generated on the titanium surfaces by the $\mathrm{O} 1 \mathrm{~s}$ binding energy after respective treatments. The binding energies for each spectrum were calibrated based on the $\mathrm{C} 1 \mathrm{~s}$ spectra of $285.0 \mathrm{eV}$.

The amount of $\bullet \mathrm{OH}$ present on the titanium samples was also determined by the following methods (Hanawa et al., 1998). Ammonium chloride solution (4 M, $500 \mathrm{~mL}$ ) was mixed with $0.4 \mathrm{M}$ zinc chloride solution $(250 \mathrm{~mL})$ and the $\mathrm{pH}$ of the mixture was adjusted with $30 \%$ ammonium hydroxide to $\mathrm{pH}$ 6.9. The volume of the mixture was adjusted to $1000 \mathrm{~mL}$ with deionized water. Titanium samples were sequentially immersed for $300 \mathrm{~s}$ in $150 \mathrm{~mL}$ of this solution in beakers at ambient temperature. During immersion, active $\bullet \mathrm{OH}$ ions were mostly exchanged for zinc ions, forming zinc chelates. After this, the plates were immersed in $150 \mathrm{~mL}$ of deionized water 3 times to remove chemical species that had not adsorbed. The specimens were dried in a desiccator. High-resolution spectra of $\mathrm{Zn}$ $2 p$ correspond to the relative zinc concentration on the titanium samples. The relative zinc concentration was 
quantified by XPS, with the amount of zinc representative of the amount of active $\cdot \mathrm{OH}$ on their surfaces.

\section{Surface topography}

The surface topography of the titanium disks was examined using a laser microscope (OLS 4000, Shimadzu). The areabased parameters measured were the average roughness (Sa), maximum peak height (Sp), maximum valley depth (Sv) and peak to valley depth (Sz), which were quantified using the proprietary software of these instruments.

\section{Measurement of contact angle}

The contact angles of the samples with or without storage in a sealed desiccator for one week, relative to $1 \mu \mathrm{L}$ of pure distilled water were measured by a contact-angle meter (CA-DT, Kyowa Interface Science, Saitama, Japan). During these measurements, the temperature and humidity were kept at $23{ }^{\circ} \mathrm{C}$ and $50 \%$, respectively.

\section{Osteoblastic cell culture}

Primary calvarial osteoblasts were obtained from the calvariae of neonatal ddY mice (Sankyo Co. Inc., Tokyo, Japan) using $0.1 \%$ collagenase and $0.2 \%$ dispase (Suda et al., 1997). Primary osteoblast cells were cultured in $\alpha$-minimum essential medium (Wako Pure Chemical Industries Ltd., Osaka, Japan) supplemented with $10 \%$ fetal bovine serum (Invitrogen, Carlsbad, CA, USA) and penicillin-streptomycin at $37{ }^{\circ} \mathrm{C}$ in a $\mathrm{CO}_{2}$ incubator $(5 \%$ $\mathrm{CO}_{2}, 95 \%$ air). At sub-confluence, cells were detached and seeded at $4 \times 10^{4}$ cells $/ \mathrm{cm}^{2}$ onto titanium samples and polystyrene cell culture plates (control) in culture medium supplemented with $50 \mu \mathrm{g} / \mathrm{mL}$ ascorbic acid, $10 \mathrm{mM} \mathrm{Na}-$ $\beta$-glycerophosphate and $10^{-8} \mathrm{M}$ dexamethasone. Culture medium comprising $200 \mathrm{ng} / \mathrm{mL}$ of purified recombinant human bone morphogenetic protein-2 (BMP2) (Astellas Pharmaceuticals Co. Ltd., Tokyo, Japan) or $200 \mathrm{ng} /$ $\mathrm{mL}$ BMP2 and $4 \mu \mathrm{g} / \mathrm{mL}$ of recombinant human lysyl oxidase homolog (LOXL2) (\#2639-AO; R\&D Systems, Minneapolis, MN, USA) with Ti specimens served as the Ti-BMP2 and TiBMP2+LOXL2 samples, respectively (Shibata et al., 2013). Culture medium was renewed every 3 days.

\section{Quantitative real-time polymerase chain reaction PCR (qPCR)}

Gene expression was analyzed and quantified by qPCR. Total RNA samples were extracted with TRIzol reagent (Invitrogen), then reverse-transcribed using SuperScript III (Invitrogen). qPCR assays were performed using a SYBR green Fast PCR system (Applied Biosystems, Foster City, CA, USA), with primer sequences shown in Table 1. Band intensity for each gene was quantified and normalized with the reference to Gapdh mRNA expression at day 3 and 1 week.

\section{Microarray analysis}

The Agilent DNA Microarray was analyzed as previously described (Shibata et al., 2013).

\section{Mineralization assay}

Alizarin red staining was performed at 2 weeks of culture. Following three washes with PBS and two washes with pure distilled water, the titanium samples were dried in air, and then stained for 5 min using $1 \%$ Alizarin Red S (Sigma-Aldrich, St Louis, MO, USA; $\mathrm{pH}=6.3-6.4$ ). The quantification of staining has been detailed in a previous study (Jang et al., 2014).

\section{Calvarial bone specimen preparation}

Two male ddY mice (Sankyo Co. Inc.) at 2 weeks and 4 weeks of age were euthanized following an approved protocol at Showa University. The calvariae were harvested with the surrounding soft tissue and then stored in Hanks' Balanced Salt Solution (Sigma-Aldrich) until use. The calvariae were cross-sectioned in the longitudinal direction using a low-speed diamond saw (Isomet; Buehler $\mathrm{GmbH}$, Braunschweig, Germany) under water irrigation. The cross-sectioned samples were embedded in a cold-cure epoxy resin (Palapress, Vario; Heraeus Kulzer GmbH, Hanau, Germany), polished manually with silicone carbide paper from $\# 800$ to $\# 1000$, and then polished with $0.3 \mu \mathrm{m}$ alumina polishing paste (Buehler). The samples were ultrasonically cleaned with distilled water for $10 \mathrm{~s}$ between each step.

Table 1. Primer sequences used for qPCR analysis of osteoblast gene expression.

\begin{tabular}{|c|c|}
\hline Gene target & Primer sequence \\
\hline Gapdh & 5'-AAATGGTGAAGGTCGGTGTG-3' and 5'-TGAAGGGGTCGTTGATGG -3' \\
\hline Osterix (Osx) & 5'-TGGCGTCCTCTCTGCTTGA-3' and 5'-CTAGAGCCGCCAAATTTGCT-3' \\
\hline Osteopontin (Opn) & 5'-GCTTTTGCCTGTTTGGCATT-3' and 5'-AGCTGCCAGAATCAGTCACTTTC-3' \\
\hline Osteocalcin (Ocn) & 5'-CTGACAAAGCCTTCATGTCCAA-3' and 5'-GGTAGCGCCGGAGTCTGTT-3' \\
\hline Bone sialoprotein 2 (Bsp2) & 5'-GAGTTAGCGGCACTCCAACTG-3' and 5'-CACTTTTGGAGCCCTGCTTT-3' \\
\hline Alkaline phosphatase (Alp) & 5'-TTCCCACGTTTTCACATTCG-3' and 5'-GCCAGACCAAAGATGGAGTTG-3' \\
\hline Lysyl oxidase (Lox) & 5'-TGCGCTGCGGAAGAAAA-3' and 5'-TCTGACATCCGCCCTATATGC-3' \\
\hline Lysyl oxidase like 1 (Loxl1) & 5'-CAGTGGATCGACATAACTGATGTG-3' and 5'-GGGTTCACGTGCACCTTGA-3' \\
\hline Lysyl oxidase like 2 (Loxl2) & 5'-CCTCAAGGTTCCGGAAAGC-3' and 5'- ACCTCTCAGGCGCACCAA -3' \\
\hline Lysyl oxidase like 3 (Loxl3) & 5'-GCGCCTTCCCGGTTTCT-3' and 5'- CACCTCCTCCACTTGCAACTG -3' \\
\hline Lysyl oxidase like 4 (Loxl4) & 5'-TTGCTCTCAAGGACACCTGGTA-3' and 5'-GCAGCGAACTCCACTCATCA-3' \\
\hline
\end{tabular}




\section{Micro-Raman spectroscopy}

Mineralized tissues, after 2 weeks of cell culture, stained with alizarin red (see Mineralization assay), were used for the micro-Raman spectroscopy tests, so that we could readily focus on the mineralized nodules on the sample surfaces. The titanium samples were also cross-sectioned, with the mineralized tissues, and then embedded in cold-cure epoxy resin (Palapress, Vario; Heraeus Kulzer $\mathrm{GmbH})$. The embedded samples were polished manually with silicone carbide paper from \# 800 to \# 1000, and then polished with $0.3 \mu \mathrm{m}$ alumina polishing paste (Buehler). Raman spectra of at least five mineralized nodules in each sample were acquired using a confocal Raman microscope (RXN1; Kaiser Optical Systems, Inc., Ann Arbor, MI, USA) with a $785 \mathrm{~nm}$ laser diode source. A $50 \times$ objective focused light on a $3 \mu \mathrm{m}$ spot on the mineralized nodules. The Raman scattered light ( $10 \mathrm{~s}$ exposure time) was collected by a spectrograph with a spectral resolution of $1 \mathrm{~cm}^{-1}$. From each Raman transect, a normalized mean spectrum was generated to offset the effect of a single spectrum on the arithmetic mean. Data for each transect were imported into Matlab 12.1 (The MathWorks, Inc., Natick, MA, USA), wherein the spectra were corrected for dark signals and averaged into normalized spectra. Background signals were removed from the normalized spectra, using a user-defined multipoint baseline routine, and the Raman bands were fitted using a curve-fit routine if all the band intensities were non-negative and the fit yielded an R2 value of 0.99 or greater. Raman shift assignments on mineralized nodules were identified from previous studies (Shibata et al., 2013).

Raman maps (HoloMap ${ }^{\mathrm{TM}}$, Kaiser Optical Systems) were generated on the cross-sectioned samples at the interface between the mineralized tissue and the titanium surfaces. A $50 \times$ objective focused light on a $3 \mu \mathrm{m}$ spot for the regions of interest with $10 \times 10$ area spots used. The relative intensity ratio of the amide III band at $1250 \mathrm{~cm}^{-1}$ was visualized.

Nanoindentation test for in vitro mineralized tissues Nanoindentation experiments were generated, using a quantitative nanomechanical test instrument (TS70 TriboScope; Hysitron, Inc., Minneapolis, MN, USA) interfaced with a scanning probe microscope (SPM-9700, Shimadzu). The probe used was a diamond Berkovich indenter (Hysitron). Fused quartz acted as the standard calibration material, to determine the indenter tip area function as well as the machine compliance of the instrument (Oliver and Pharr, 1992).

The detailed nanoidentation theory on mineralized tissue has been described previously (Shibata et al., 2013). Hydrated mineralized tissues on titanium samples, immediately after 2 weeks of cell culture, were used for nanoindentation tests. The tissues were not subjected to fixation with chemicals such as aldehyde or ethanol, because such fixations would increase or decrease the elastic properties of the tissues because of conformational changes to the collagen molecules. The nanoindentation tests were also performed on parietal (cortical) regions of the calvarial bone samples used in the study.

The indentation tests were performed perpendicular to the sample surface using a partial unloading technique (Field and Swain, 1995) with a load function comprising an incremental 33 loading and unloading cycles with a hold time. Each segment time was set at $1 \mathrm{~s}$, and maximum loading force was $1 \mathrm{mN}$ (Jang et al., 2014).

The hardness and elastic modulus were calculated from the force-displacement curves using the standard unloading analysis within the TS-70 proprietary software (Hysitron). The values for at least five indentation tests were merged and the error bars were shown as a bar chart to indicate the deviation of the data between 40 and $150 \mathrm{~nm}$, based on the effective range of the Berkovich tip area function used in this study.

\section{Statistical analysis}

Three samples were evaluated in the surface characterization experiments and the cell culture studies (mineralization assay, qPCR) while five tests were performed in the nanoindentation studies. Results are expressed as the mean \pm SD for each experiment. The normal distribution of each value was confirmed using the Kolmogorov-Smirnov test. The appropriateness of the hypothesis of homogeneous variances was investigated by means of the Bartlett's test. Data were statistically analyzed by ANOVA followed by a post-hoc Tukey test. A $p$ value of less than 0.05 was considered significant.

\section{Results}

\section{Surface characterization}

\section{Thin-film X-ray diffraction (TF-XRD)}

The $2 \theta$ values of the $\mathrm{TiO}$ suboxide peaks were more distinct with Ao-Ti, Ho-Ti and Ao-Heat than with Ti samples. A peak around $27^{\circ}$, attributed as rutile $\mathrm{TiO}_{2}$, was observed on Ho-Ti. A broad peak around $25^{\circ}$, that could be attributed to a range of d-spacing for the amorphous matrix between anatase and rutile, was observed on Ao-Ti. Two peaks, attributed as a crystal anatase $\mathrm{TiO}_{2}$ phase, were detectable around $37^{\circ}$ and $53^{\circ}$ on Ao-Heat (Fig. 1a). The increasing $\mathrm{TiO}$ and $\mathrm{TiO}_{2}$ revealed the developing thickness of the titanium oxide film on the oxidized titanium samples.

\section{ROS detection on titanium surfaces by XPS}

According to the O1s spectra obtained from the samples before storage, the main chemical species on Ti were postulated to be $\mathrm{O}^{2-}, \mathrm{OH}^{-}$and $\mathrm{H}_{2} \mathrm{O}$ (McCafferty and Wightman, 1999; Okawa and Watanabe, 2009). The binding energy values corresponding to the $\mathrm{O}^{2-}, \mathrm{OH}^{-}$and $\mathrm{H}_{2} \mathrm{O}$ peaks were $530.3,532.2$ and $533.2 \mathrm{eV}$, respectively. The main chemical species on Ho-Ti were postulated to be $\mathrm{O}^{2-}, \cdot \mathrm{OH}$ (see Experimental section) and $\mathrm{OH}^{-}$. The binding energy values corresponding to the $\mathrm{O}^{2-}, \cdot \mathrm{OH}$ and $\mathrm{OH}^{-}$peaks were 530.3, 531.4 and $533.2 \mathrm{eV}$, respectively (Hanawa et al., 1998; Lin and Bumgardner, 2004; McCafferty and Wightman, 1999; McCarron, 1990; Ohtsuki et al., 1997; Park et al., 2007; Takemoto et al., 2004). The main $\mathrm{O}^{2-}$ species at $530.3 \mathrm{eV}$ on Ti and Ho-Ti originated from the $\mathrm{TiO}_{2}$ superficial oxide film (not shown). 


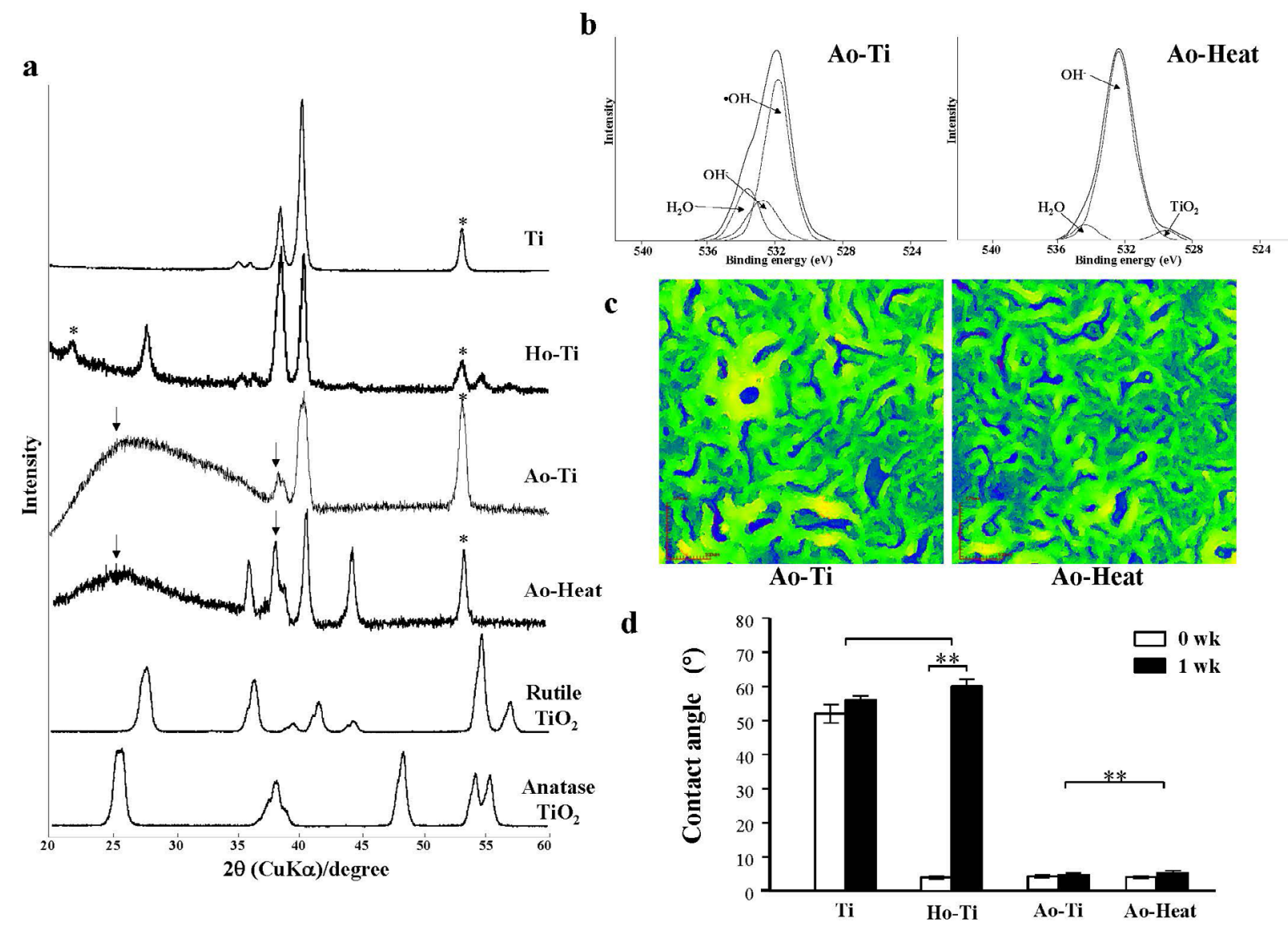

Fig. 1. Surface characterization of titanium samples. XRD spectra of titanium samples (a). Pure rutile and anatase $\mathrm{TiO}_{2}$ particles were used as standard reference materials. Peaks attributable to an anatase $\mathrm{TiO}_{2}$ crystal phase (arrow) were detected on Ao-Ti and Ao-Heat. The increasing $\mathrm{TiO}$ (asterisk) and anatase $\mathrm{TiO}_{2}$ revealed a developing thickness of the titanium oxide film on Ao-Ti and Ao-Heat. High resolution XPS spectra of O1s on Ao-Ti and Ao-Heat (b). The binding energy values corresponding to $\mathrm{TiO}_{2}, \cdot \mathrm{OH}, \mathrm{OH}^{-}$and $\mathrm{H}_{2} \mathrm{O}$ peaks were 530.3, 531.4, 532.2 and $533.2 \mathrm{eV}$, respectively. The surface topography of the titanium samples was examined using a laser microscope (c). Contact angle of pure distilled water on the titanium samples before storage $(0 \mathrm{wk})$ and after 1 week $(1 \mathrm{wk})$ of storage (d). The mean values are shown with the standard deviation $(n=3 * p<0.05, * * p<0.01)$.

Table 2. Relative atomic concentrations of each element ( $\%)$ on the titanium samples, with $(+)$ or without immersion in a solution containing ammonium chloride and zinc chloride. Results are expressed as the mean $\pm \mathrm{SD}$ of three independent repeats $(n=3)$. Data were statistically analyzed by ANOVA followed by a post-hoc Tukey test.

\begin{tabular}{|l|r|l|l|l|l|}
\hline & \multicolumn{1}{|l|}{$\mathrm{Ti}$} & $\mathrm{O}$ & $\mathrm{C}$ & $\mathrm{P}$ & $\mathrm{Zn}$ \\
\hline $\mathrm{Ti}$ & $13.9 \pm 0.4$ & $54.5 \pm 2.8$ & $31.6 \pm 2.1$ & - & - \\
\hline Ho-Ti & $23.6 \pm 1.3$ & $61.3 \pm 3.1$ & $15.1 \pm 1.9$ & - & - \\
\hline Ao-Ti & $6.2 \pm 0.8$ & $59.2 \pm 3.8$ & $15.5 \pm 2.2$ & $15.6 \pm 3.1$ & - \\
\hline Ao-Heat & $4.2 \pm 1.8$ & $60.3 \pm 2.2$ & $18.7 \pm 1.2$ & $12.5 \pm 2.8$ & - \\
\hline Ti $(+)$ & $10.2 \pm 1.6$ & $43.6 \pm 4.2$ & $44.5 \pm 5.4$ & - & $1.6 \pm 0.4$ \\
\hline Ho-Ti $(+)$ & $9.8 \pm 0.9$ & $40.7 \pm 2.2$ & $47.1 \pm 3.2$ & - & $2.2 \pm 0.7$ \\
\hline Ao-Ti $(+)$ & $2.7 \pm 0.6$ & $40.4 \pm 3.1$ & $40.3 \pm 4.1$ & $11.3 \pm 1.2$ & $5.2 \pm 1.4$ \\
\hline Ao-Heat $(+)$ & $4.7 \pm 2.3$ & $40.5 \pm 4.4$ & $43.1 \pm 2.2$ & $9.3 \pm 2.2$ & $2.1 \pm 1.1$ \\
\hline
\end{tabular}

The main chemical species on Ao-Ti were postulated to be $\mathrm{OH}, \mathrm{OH}^{-}$and $\mathrm{H}_{2} \mathrm{O}$. The binding energy values corresponding to the $\cdot \mathrm{OH}, \mathrm{OH}^{-}$and $\mathrm{H}_{2} \mathrm{O}$ peaks were 531.4, 532.2 and $533.2 \mathrm{eV}$, respectively (Fig. 1b). The presence of ROS, such as $\bullet \mathrm{OH}$ and their oxidation products (He et al., 2008; Lin and Bumgardner, 2004; McCarron, 1990), was increased on the Ao-Ti sample in comparison with $\mathrm{Ti}$ and Ho-Ti. The peaks attributed to the formation of $\bullet \mathrm{OH}$ were not detectable on Ao-Heat, although $\mathrm{OH}^{-}$was still detectable on the surface (Fig. 1b).

After immersion in a solution containing ammonium chloride and zinc chloride, the relative concentration of zinc on Ao-Ti was significantly higher $(p<0.01)$ than that on Ti, Ho-Ti, and Ao-Heat (Table 2) (Jang et al., 2014). 
$\mathbf{a}$
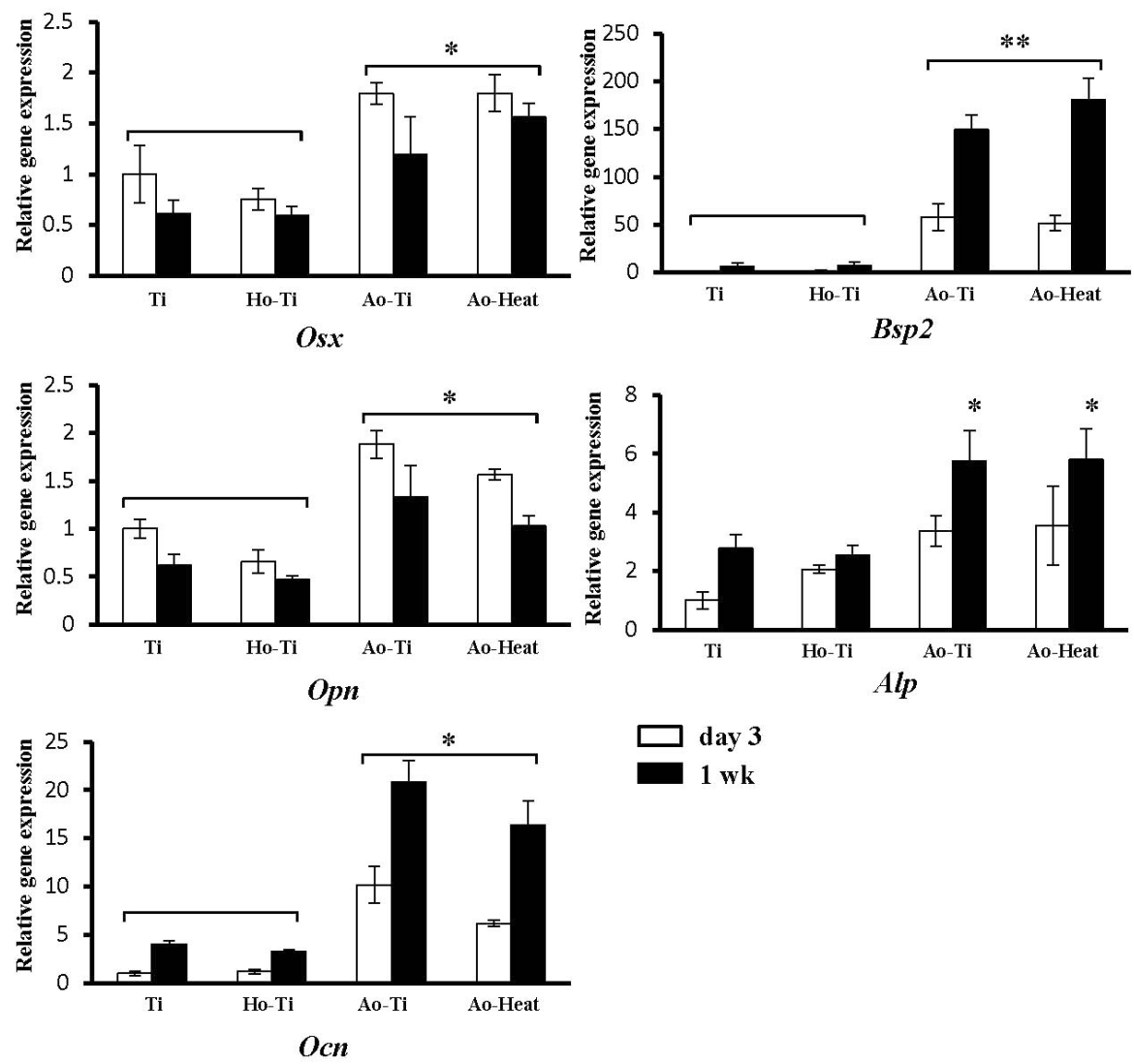

$\square$ day 3

$1 \mathrm{wk}$

b

Fig. 2. (a) Gene expression profiles of osteoblasts on titanium samples. Relative gene expression on day 3 and 1 week ( $1 \mathrm{wk}$ ) of osteoblast culture were evaluated by qPCR. The mean relative fold changes in mRNA expression after normalization to Gapdh expression are shown with the standard deviation $(n=3 * p<0.05, * * p<0.01)$. (b) Gene expression profiles of osteoblasts on titanium samples. Gene scatter plots from polystyrene culture plates (control) and titanium samples on day 3 of osteoblast culture.
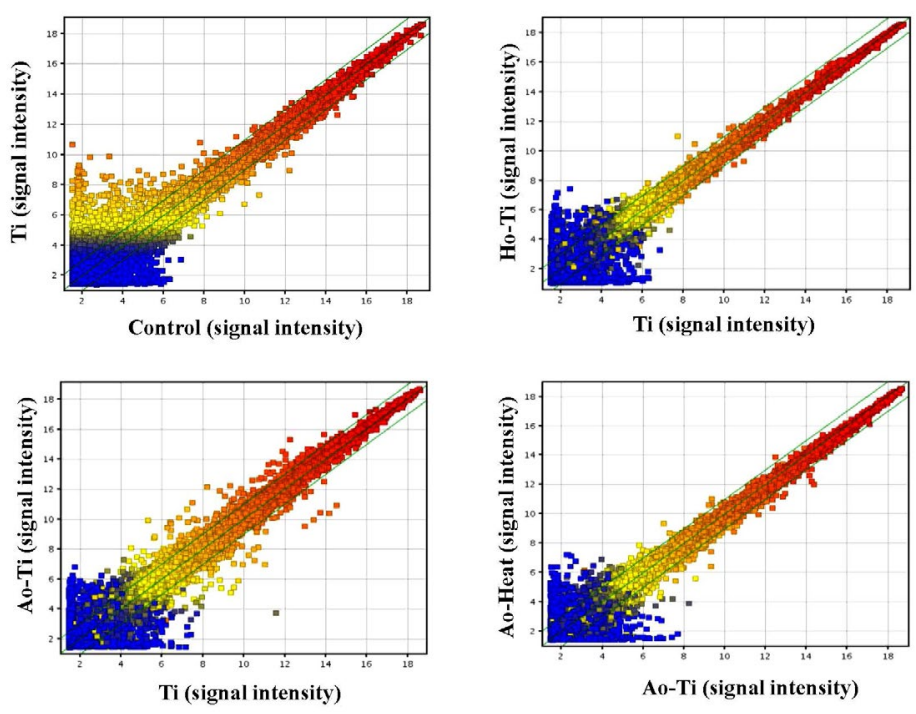

Ao-Ti (signal intensity)

Hence, the increased amount of $\bullet \mathrm{OH}$ generated on the AoTi could also be clarified (Hanawa et al., 1998).

\section{Surface topography}

Pores with diameters in the micron or submicron scale were counted on Ao-Ti and Ao-Heat (Fig. 1c). The mean surface roughness parameters are summarized in Table 3. The roughness parameters on Ao-Ti and Ao-Heat were higher $(p<0.01)$ than those values on Ti and Ho-Ti. However, those parameters between Ao-Ti and Ao-Heat were statistically equivalent $(p>0.01)$.
Table 3. Mean surface roughness parameters of titanium samples. The average roughness $(\mathrm{Sa})$, root mean square deviation (Sq), maximum peak height (Sp), maximum valley depth (Sv) and peak to valley depth $(\mathrm{Sz})$ were quantified using the proprietary software of these instruments with a scanning range of $643 \times 644 \mu \mathrm{m}(n=3)$.

\begin{tabular}{|l|c|c|c|c|}
\hline & $\mathbf{S p}(\boldsymbol{\mu m})$ & $\mathbf{S v}(\boldsymbol{\mu m})$ & $\mathbf{S z}(\boldsymbol{\mu m})$ & $\mathbf{S a}(\boldsymbol{\mu m})$ \\
\hline Ti & 3.56 & 2.94 & 6.50 & 0.30 \\
\hline Ho-Ti & 3.05 & 2.79 & 5.84 & 0.34 \\
\hline Ao-Ti & 25.70 & 19.69 & 45.40 & 4.36 \\
\hline Ao-Heat & 25.50 & 19.28 & 46.20 & 4.65 \\
\hline
\end{tabular}



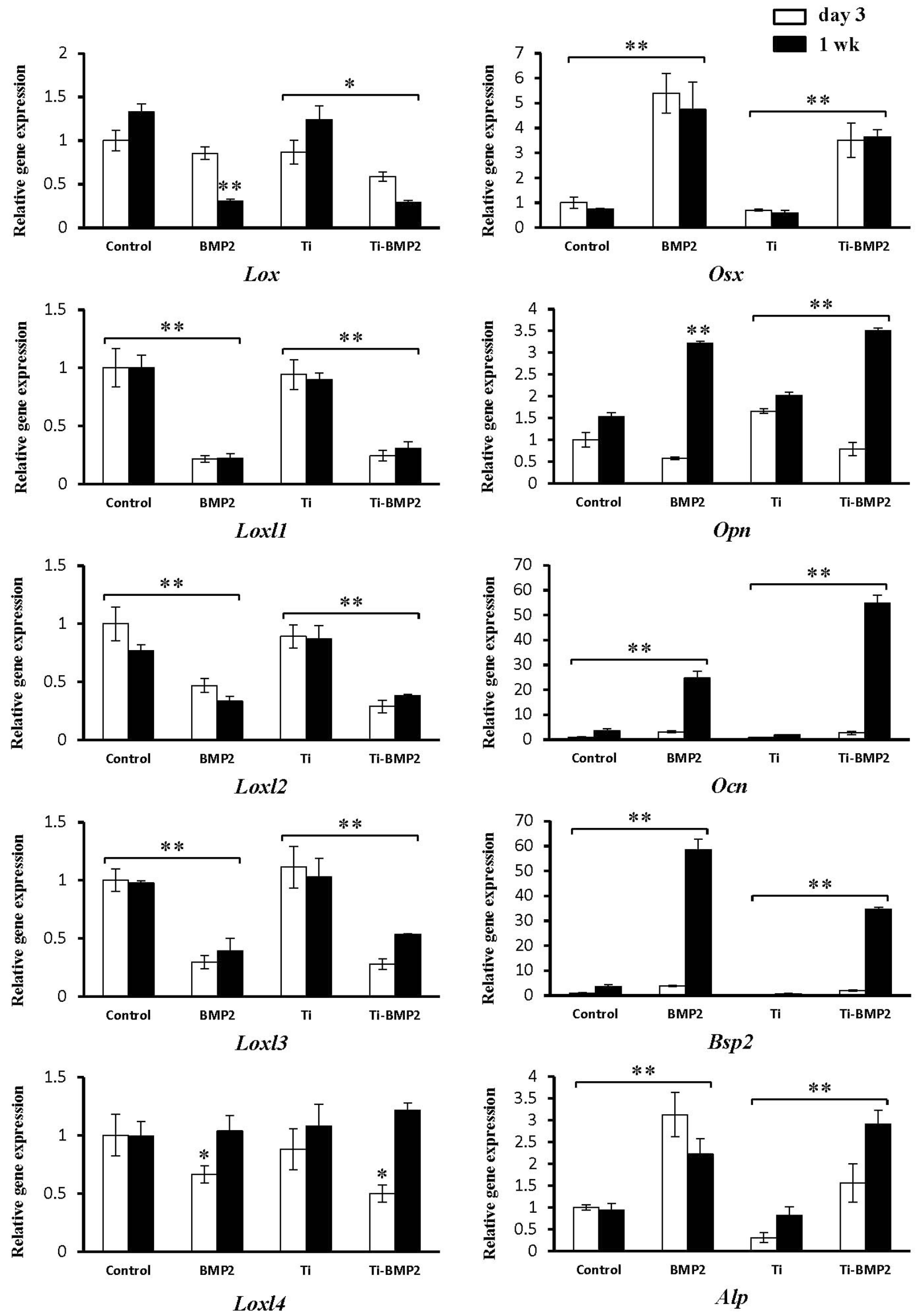

Fig. 3. Gene expression of osteoblasts on Ti and Ti with BMP2 (Ti-BMP2) or gene expressions of osteoblasts on polystyrene culture plates (control) with or without BMP2 evaluated by qPCR. Relative gene expressions on day 3 and 1 week ( $1 \mathrm{wk})$ of osteoblast culture are shown. The mean relative fold changes in mRNA expressions after normalization to Gapdh expression are shown with the standard deviation $(n=3 * p<0.05, * * p<0.01)$. 


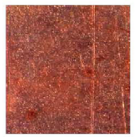

Ti

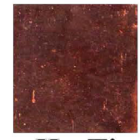

Ho-Ti

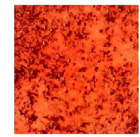

A0-Ti

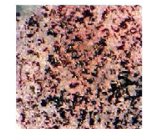

Ao-Heat

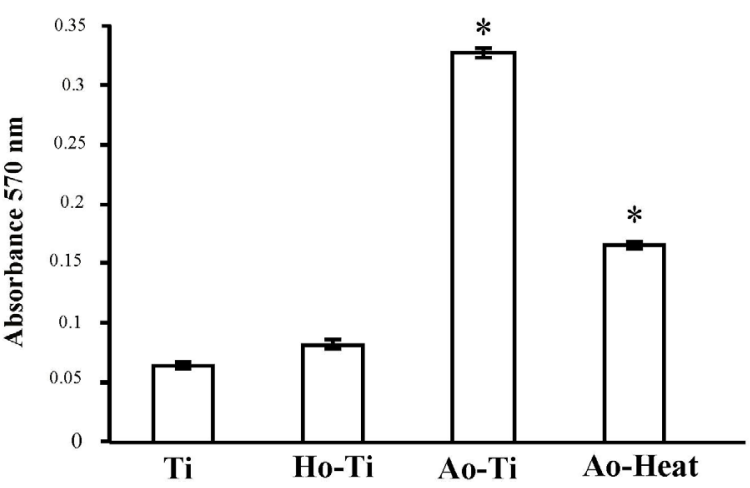

b

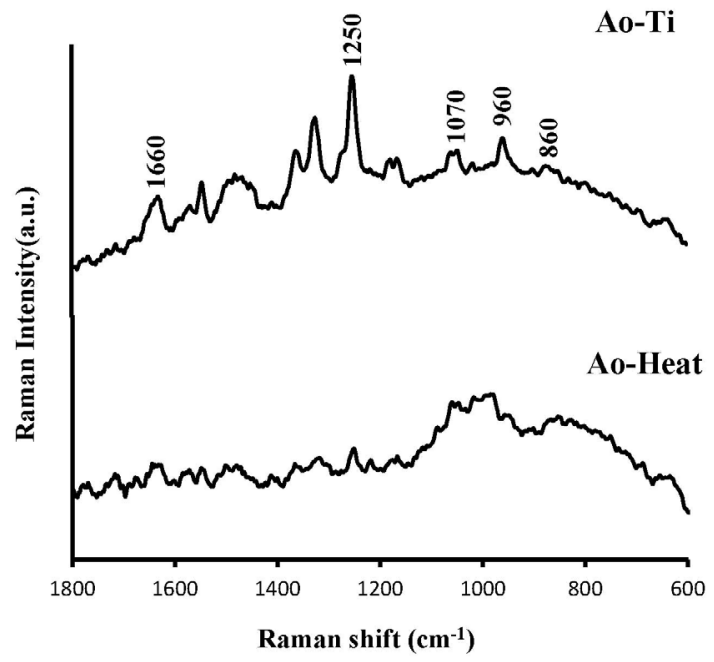

Fig. 4. Mineralized nodules on titanium samples. (a) Representative pictures and quantification of Alizarin red staining of the samples after 2 weeks of cell culture shown with the standard deviation $(n=3$ $* p<0.05,{ }^{* *} p<0.01$ ). (b) A representative Raman spectrum between 600 and $1800 \mathrm{~cm}^{-1}$ of the mineralized nodules on Ao-Ti and Ao-Heat. Amide I $\left(1660 \mathrm{~cm}^{-}\right.$ $\left.{ }^{1}\right)$, Amide III (1250 $\left.\mathrm{cm}^{-1}\right)$, B-type carbonate $\left(1070 \mathrm{~cm}^{-1}\right)$, proline $\left(856 \mathrm{~cm}^{-1}\right)$, and the $v_{1}$ phosphate $\left(960 \mathrm{~cm}^{-1}\right)$ were detectable on Ao$\mathrm{Ti}$, whereas no distinctive spectra were observed on Ao-Heat. (c) Cross-sectioned titanium samples after 2 weeks of cell culture. Raman maps at the interface between in vitro mineralized tissues and the titanium surface. The relative intensity of amide III $\left(1250 \mathrm{~cm}^{-1}\right)$ is visualized.
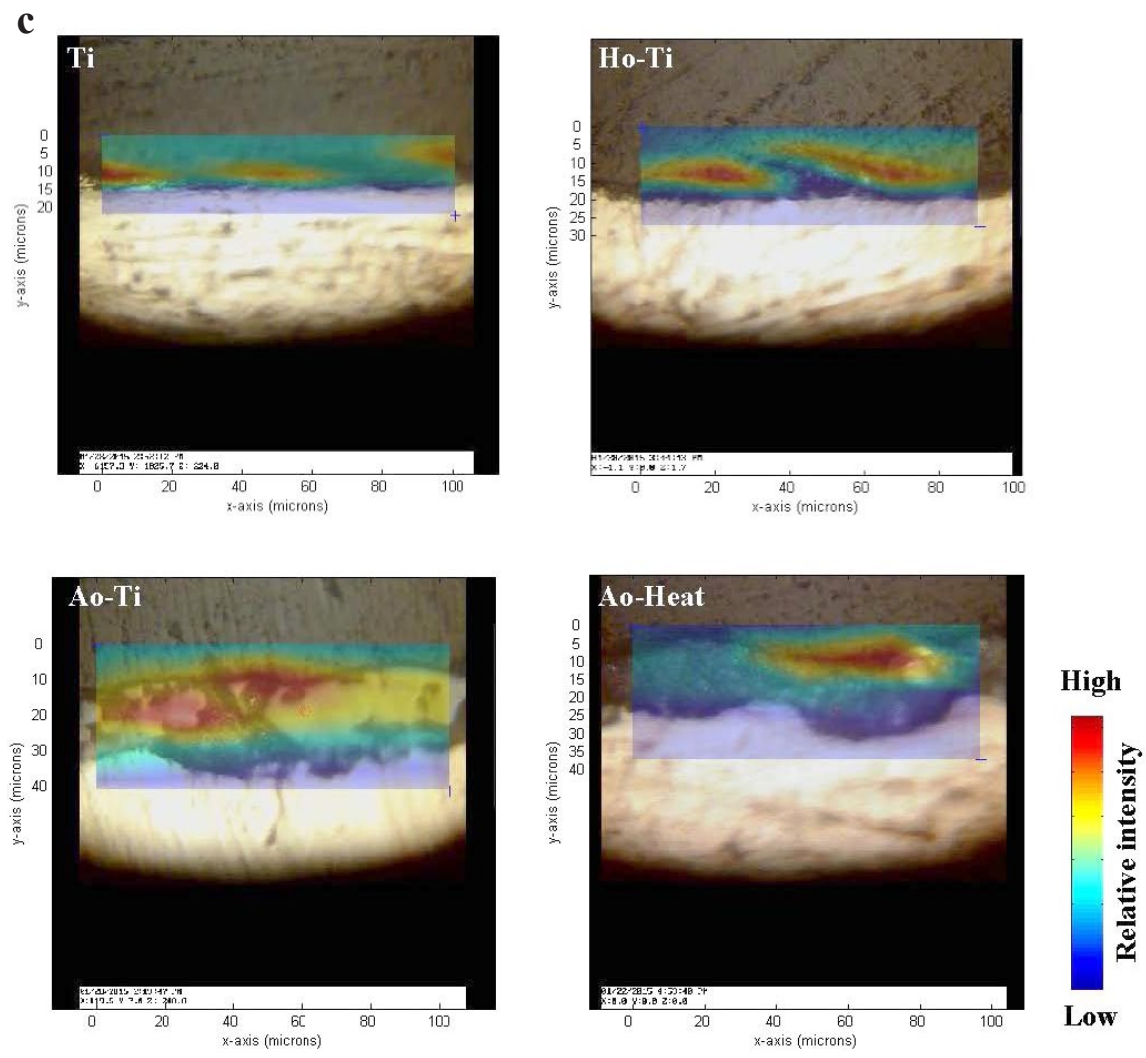

Measurement of contact angle

The contact angle of pure distilled water on the oxidized samples before storage was $<5^{\circ}$, whereas that of Ti was $52 \pm 1.0^{\circ}$. The oxidized samples showed significantly higher hydrophilicity $(p<0.01)$ compared with titanium samples (Fig. 1d). However, Ho-Ti showed a great reduction of surface hydrophilicity after 1 week of storage as the contact angle of Ho-Ti to pure distilled water increased significantly $(p<0.01)$.

\section{Osteoblast phenotype on titanium samples}

At day 3 of culture, the expression levels of osterix $(\mathrm{Osx})$, osteopontin (Opn), osteocalcin (Ocn), and bone sialoprotein-2 (Bsp2) on the Ao-Ti and Ao-Heat surfaces were significantly higher $(p<0.01,0.05)$ than those on the Ti and Ho-Ti surfaces (Fig. 2a). At 1 week of culture, Osx, Opn, Ocn, Bsp2, and alkaline phosphatase (Alp) expression levels on the Ao-Ti and Ao-Heat surfaces were significantly higher than those on the $\mathrm{Ti}$ and Ho-Ti surfaces. The expression between Ao-Ti and Ao-Heat was statistically equivalent $(p>0.05)$.

Concerning osteoblast phenotypes cultured on bare titanium and control cell culture plates with supplemental BMP2, qPCR analyses also verified the downregulation of LOX family gene expression including Lox, Loxl1, Loxl2, Loxl3, and Loxl4 by BMP2, and this was concomitant with 
a
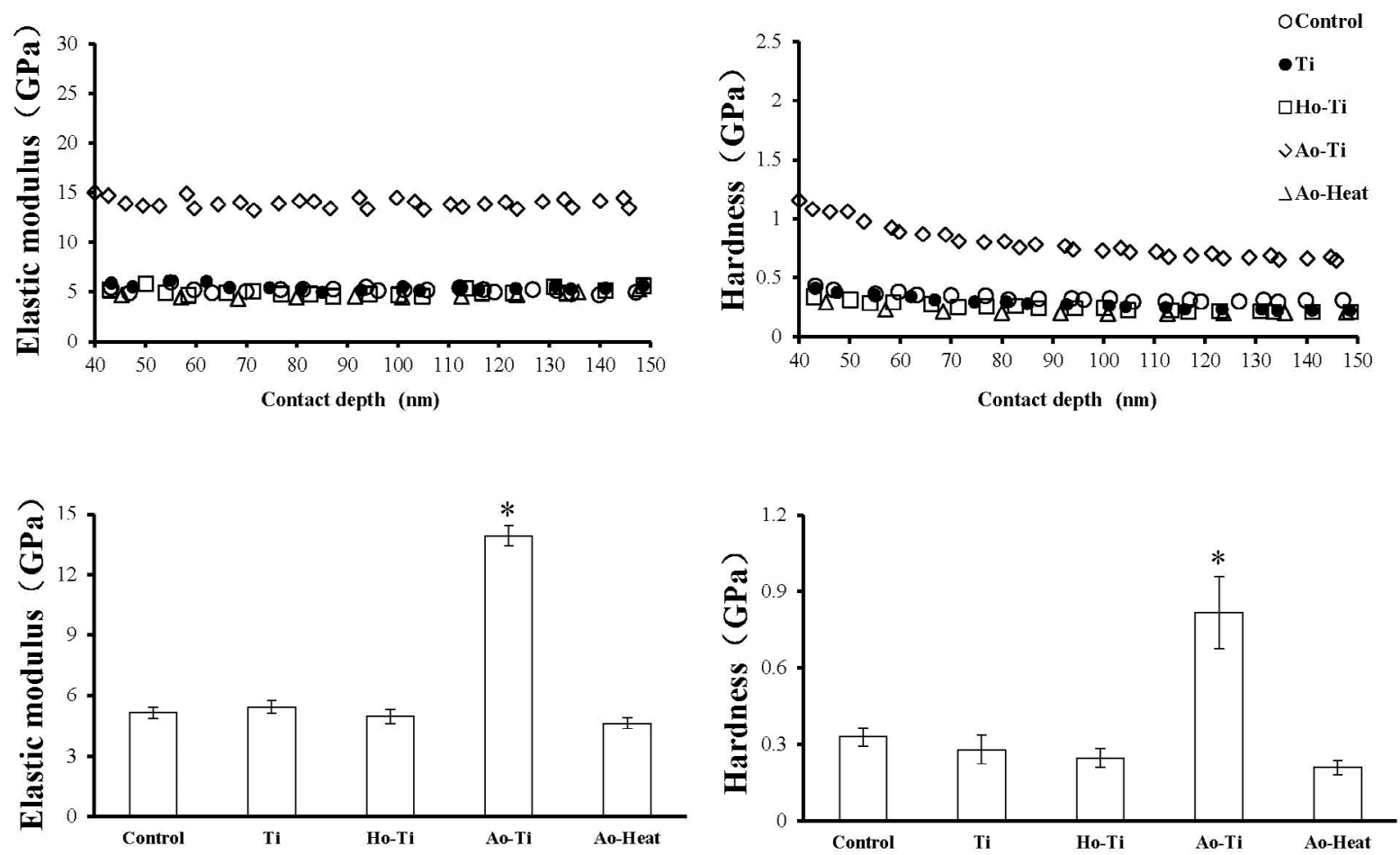

b
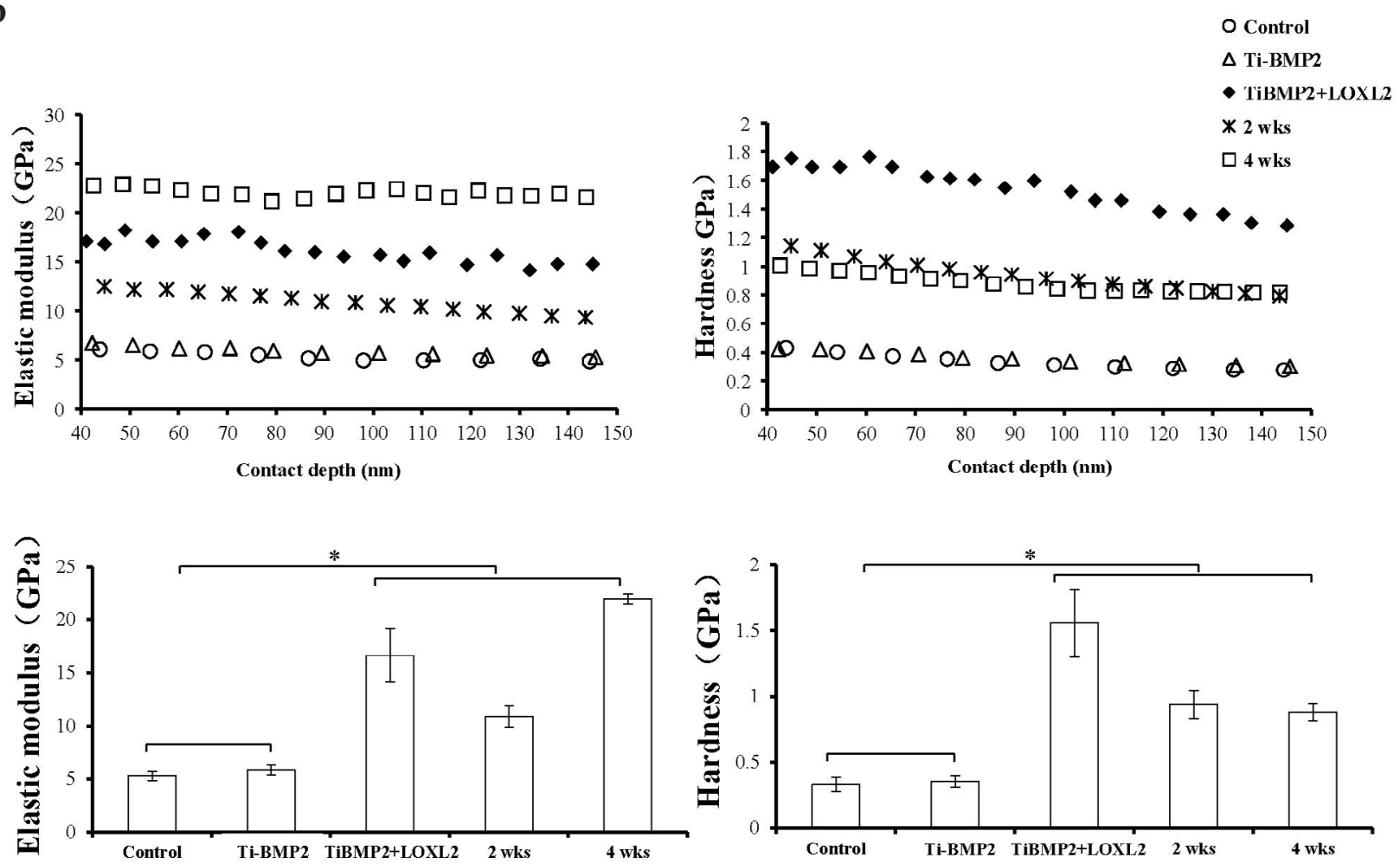

Fig. 5. (a) Nanomechanical properties of the mineralized tissues. Hardness and elastic modulus data vs. contact depth of mineralized tissues on polystyrene culture plate (control) and titanium samples after 2 weeks of cell culture obtained by the partial unloading technique (upper panels). The average values of mineralized tissues on control and titanium samples after 2 weeks of cell culture obtained by the partial unloading technique between 40 and $150 \mathrm{~nm}$ with the standard deviation $(n=5 * p<0.05, * * p<0.01)$ (lower panels). (b) Hardness and elastic modulus data $v s$. contact depth of mineralized tissues on the control, Ti specimens cultured with BMP2 (Ti-BMP2), with BMP2 and LOXL2 (TiBMP2+LOXL2), and calvarial bone samples at 2 weeks ( 2 wks) and 4 weeks of age (4 wks) obtained by the partial unloading technique (upper panels). The average values of mineralized tissues after 2 weeks of cell culture and calvarial bone obtained by the partial unloading technique between 40 and $150 \mathrm{~nm}$ with the standard deviation $(n=5 * p<0.05, * * p<0.01)$ (lower panels). 
enhanced expression of osteoblast differentiation marker genes including $O s x, O p n, O c n, B s p 2$, and $A l p$ as compared with control or Ti cultures (Fig. 3).

\section{DNA microarray}

Gene scatter plots showed that Ti vs. Ao-Ti had large numbers of upregulated and downregulated genes in cells, as indicated by the regions outside the central area; whereas other comparisons, including control vs. Ti, Ti vs. Ho-Ti, and Ao-Ti vs. Ao-Heat exhibited almost similar expression levels (Fig. 2b). After adopting cut-off points of $\times 2.0$ and $\times 0.5$, the overlap of differentially upregulated or downregulated genes between Ti vs. Ao-Ti and Ho-Ti vs. Ao-Ti indicated a total number of 653 upregulated genes (not shown). Gene ontology (GO) analysis of these overlapping genes revealed a total of 209 upregulated GO terms that satisfied a corrected $p$-value of 0.1 , and these upregulated GO terms covered categories of ossification, tissue development, and cell differentiation-related genes, such as $O s x$ and $O c n$, as well as those observed in qPCR. Ao-Ti vs. Ao-Heat displayed a total of 21 upregulated GO terms, but none of the downregulated GO terms satisfied a corrected $p$-value of 0.1 . The upregulated GO terms for Ao-Ti vs. Ao-Heat were not involved in the categories of ossification, tissue development, or cell differentiationrelated genes.

\section{Mineralization assay}

The area of mineralized nodule formation on Ao-Ti and AoHeat surfaces was observed to be greater than that observed on Ti and Ho-Ti surfaces, with the area of mineralization on Ao-Ti significantly greater than that on Ao-Heat (Fig. 4a). This observation was verified with quantification, with Ao-Ti and Ao-Heat surfaces having a significantly higher $(p<0.05)$ quantifiable mineralized area than Ti and Ho-Ti surfaces.

\section{Nanoindentation test}

After 2 weeks of cell culture, we calculated the representative hardness and elastic modulus of the mineralized tissues developing on the titanium samples using depth-dependent partial loading curves. The hardness and elastic modulus of the bare Ti surface were $3.1 \pm 0.3$ and $178.8 \pm 4.5 \mathrm{GPa}$, respectively (data not shown). The hardness and elastic modulus (40-150 nm contact depth) of mineralized tissues on Ti were $0.25 \pm 0.06$ and $4.8 \pm 0.05 \mathrm{GPa}$, respectively, while those on Ho-Ti were $0.24 \pm 0.04$ and $5.5 \pm 0.04 \mathrm{GPa}$, respectively (Fig. 5a). In addition, the hardness and elastic modulus of the mineralized tissue on Ao-Ti were $0.25 \pm 0.06$ and $4.8 \pm 0.05 \mathrm{GPa}$, respectively. There were no significant differences $(p>0.01)$ in the nanomechanical properties of any of the mineralized tissues grown on the polystyrene culture plate (control) Ti, Ho-Ti, Ao-Heat surfaces. The hardness and elastic modulus of the mineralized tissue on Ao-Ti were significantly higher $(p<0.05)$ than those of Ti, Ho-Ti and Ao-Heat, being estimated at $0.78 \pm 0.04$ and $13.5 \pm 0.08 \mathrm{GPa}$, respectively. The latter values were comparable to those of the 2-week-old calvarial bone sample and those of human bone or dentin reported in previous studies (Angker et al., 2005; Butz et al., 2006; Shibata et al., 2008). The lowest values for the hardness and elastic modulus $(p<0.05)$ were obtained on mineralized tissue samples cultured in the presence of BMP2 (Fig. 4b). These values could be distinguished from the underlying polystyrene culture plate $(p<0.01)$ (data not shown). The mineralized tissues in the TiBMP2+LOXL2 samples had the highest hardness and elastic modulus of 1.6 and 18.0 GPa, respectively. The latter values were comparable to those of the 4-week-old calvarial bone sample (Fig. 5b).

\section{Molecular structure of mineralized nodules}

There were no distinctive Raman spectra observed on the Ti and Ho-Ti specimens, even after 2 weeks of culture (not shown). Representative Raman spectra (between 600 and $1800 \mathrm{~cm}^{-1}$ ) of mineralized nodules on Ao-Ti and Ao-Heat are shown. Amide I $\left(1660 \mathrm{~cm}^{-1}\right)$, Amide III $\left(1250 \mathrm{~cm}^{-1}\right)$, B-type carbonate $\left(1070 \mathrm{~cm}^{-1}\right)$, proline $\left(856 \mathrm{~cm}^{-1}\right)$, and the $v_{1}$ phosphate $\left(960 \mathrm{~cm}^{-1}\right)$ (Bonifacio et al., 2010; Dehring et al., 2006) were detectable on Ao-Ti whereas no distinctive spectra were observed on Ao-Heat (Fig. 4b). Raman maps revealed tight connections between the mineralized nodules and the titanium sample surfaces (Fig. 4c).

\section{Discussion}

In the present study, we investigated the nanomechanical properties of in vitro mineralized tissue on titanium sample surfaces. The aim of this study was to discern the individual surface characteristics of anodically oxidized titanium surfaces, such as surface wetting properties and oxidation effects, which enable osteogenic cell differentiation and enhanced matrix cross-linking, respectively. A tight connection between mineralized tissues and anodically oxidized titanium surfaces was observed, indicating that the mineralized nodules on titanium samples were likely associated with individual surface characteristics.

The thickness of rutile $\mathrm{TiO}_{2}$ was observed on thermally oxidized Ho-Ti, whereas anatase $\mathrm{TiO}_{2}$ was detectable on anodically oxidized Ao-Ti. Anodizing by spark discharge in electrolyte enables the generation of numerous crystal phases comprising anatase, rutile and their intermediate amorphous matrices. Such varied mature and immature crystal lattices enable a range of intrinsic d-spacing. The XRD peak position is primarily based on the d-spacing, assuming that anodically oxidized titanium surfaces generated a broad peak from numerous $\mathrm{TiO}_{2}$ crystal phases at 23-25 degrees. Therefore, the anatase (or rutile) phase $\mathrm{TiO}_{2}$ in the amorphous matrix layer existed on the anodically oxidized titanium surfaces.

The superior wetting properties of the Ho-Ti surface were reduced by probable surface contamination after 1 week of storage (Att et al., 2009). Despite the initial superhydrophilicity, the in vitro biological activity of Ho$\mathrm{Ti}$ was statistically equivalent to untreated $\mathrm{Ti}$, whereas enhanced osteoblast function could be observed on anodically oxidized Ao-Ti and Ao-Heat because of the hydrophilic functional groups or surface topography.

Surface characterization on Ao-Heat revealed a reduction of $\bullet \mathrm{OH}$ on the surface, although the topographic and hydrophilic features on Ao-Heat remained similar to those on Ao-Ti. Osteogenic gene expression levels on Ao- 
$\mathrm{Ti}$ and Ao-Heat were higher than those on $\mathrm{Ti}$ and $\mathrm{Ho}-\mathrm{Ti}$, but there were no distinctive differences between Ao-Ti and Ao-Heat in the comprehensive gene expression profiles. Thus, surface topographies and hydrophilicity on Ao-Ti, rather than $\bullet \mathrm{OH}$, were responsible for changes in gene expression of adherent osteoblasts on the surface.

Although the extent of mineralization on both anodically oxidized Ao-Ti and Ao-Heat was larger than that of Ti and Ho-Ti, Ao-Ti showed the greatest degree of mineralization of adherent osteoblasts, and only AoTi demonstrated molecular features of bone-like tissue. Additionally, the nanomechanical properties of mineralized tissue on Ao-Ti were higher than those on Ao-Heat, and approached the nanomechanical properties identified with the calvarial bone sample. The obvious reduction in the nanomechanical properties of mineralized tissue on AoHeat was therefore because of the oxidation effects caused by the release of $\bullet \mathrm{OH}$.

By contrast, osteoblasts cultured with supplemental BMP2 on Ti showed enhanced osteogenic gene expression, as did those cells cultured on anodically oxidized AoTi and Ao-Heat. Despite the substantially increased osteoblast differentiation and mineralization, we observed a remarkable deterioration in the nanomechanical properties of these mineralized tissues with supplemental BMP2 and a great reduction in LOX family members in osteoblasts cultured with BMP2. However, the inferior nanomechanical properties in these Ti-BMP2 samples could be recovered with supplemental LOXL2, as seen in the TiBMP2+LOXL2 samples. LOX is a critical enzyme in the normal biosynthesis of extracellular matrix proteins (such as collagen cross-linking) by the oxidation of lysine residues (Vora et al., 2010). Because bone is a natural biocomposite consisting of mineralized collagen fibers (Dvir et al., 2011; Gower, 2008), a cross-linked collagenous matrix is therefore essential, together with the expression of specific genes that induce ossification to ensure the hardness and elastic modulus of mineralized tissues (Paschalis et al., 2003; Wang et al., 2002). A recent study reports the expression of Loxl2 by prehypertrophic and hypertrophic chondrocytes during the chondrogenic phase of bone fracture healing (Iftikhar et al., 2011). Although the biological functions of the LOX family members in bone formation have not been fully elucidated, the cooperative interaction between osteogenic differentiation and oxidation of the collagen matrix is capable of mediating harder and stiffer in vitro mineralized tissue.

During endochondral ossification, generation of ROS such as $\bullet \mathrm{OH}$ is often considered to be a biological function that enables apoptosis caused by oxidative stress (Morita et $a l ., 2007)$, based on the fact that the apoptotic cells induce subsequent osteoblast mineralization. Thus, the oxidative stress of the surface $\cdot \mathrm{OH}$ of Ao-Ti could enhance the mineralization of adherent cells to a greater extent than in the other samples. Despite the estimated oxidative stress on Ao-Ti, a previous study reported a great reduction in the oxidative stress on Ao-Ti as a consequence of oxygen diffusion into the culture medium by the invariable reaction between surface $\bullet \mathrm{OH}$ and water (Iwai-Yoshida et al., 2012).
On this basis, we conclude that the enhanced mineralization on the Ao-Ti surface was not fully associated with cell apoptosis. Apart from the apoptotic mineralization, $\bullet \mathrm{OH}$ causes the depolymerization of proteins on the titanium surface, allowing the surface to become more mineralized (Klinger et al., 1997; Tengvall et al., 1989). However, our latest study revealed that the generation of $\bullet \mathrm{OH}$ on titanium surfaces enables enhanced collagen matrix cross-linking rather than protein depolymerization (Jang et al., 2014). Thus, the surface $\bullet \mathrm{OH}$ of Ao-Ti are capable of enhancing the nanomechanical properties of mineralized tissues through the oxidation and maturation of collagenous matrix proteins.

Both the Ti-BMP2 and the Ao-Heat material enhanced the expression of osteogenic genes and increased the mineralization of cultured osteoblasts, but led to inferior nanomechanical properties in the mineralized tissues, presumably caused by reduced levels of LOX family members and $\bullet \mathrm{OH}$. Indeed, $\bullet \mathrm{OH}$ on Ao-Ti samples were shown to be critical in enhancing the nanomechanical properties of mineralized tissue, through induction of cross-linking of collagenous bone matrix proteins as well as expression of LOX family members in the ossifying tissue. Osseointegrated implants need to be functional as rigid osseous anchors. The biomechanical stability of osseointegrated titanium implants is of particular importance, especially the stability or longevity that is achieved from the physicochemical properties of the mineralized tissue at the interface between the implant surface and the host bone (Butz et al., 2006; Ozawa et al., 2002; Saruwatari et al., 2005; Shibata et al., 2008). Un-remodeled bone regions are generally very fibrous and are not replaced by mature bone. Therefore, new biomaterials for bone regenerative purposes, such as titanium implants, need to feature a surface that promotes osteogenic differentiation and enhanced mineralization during the initial integration stage. An anatase $\mathrm{TiO}_{2}$ phase in the amorphous matrix on anodically oxidized Ao-Ti surfaces showed enhanced osteogenic gene expression and better nanomechanical properties of mineralized tissue than rutile $\mathrm{Ti}$ on thermally oxidized titanium surfaces. The successful surface modification of titanium implants associated with $\bullet \mathrm{OH}$ and the common findings, such as hydrophilicity and surface topographies, could be expected on anodically oxidized Ao-Ti.

\section{Conclusions}

The present study assessed the in vitro biological activity of anodically oxidized titanium samples with or without $\cdot \mathrm{OH}$ release. $\cdot \mathrm{OH}$ on the surface of anodically oxidized titanium, prepared by discharging in an electrolyte, enhanced the nanomechanical properties of the mineralized tissues, while the surface hydrophilicity and topography changes were related to the expression of osteogenic genes by the cells. The nanomechanical properties of in vitro mineralized tissues and osteoblast behavior on modified titanium surfaces should be examined in parallel in future studies. 


\section{Acknowledgments}

This work was supported by an Iwadare Scholarship, a Grant-in-Aid for Scientific Research (B) and a Grantin-Aid for Scientific Research (C) from the Ministry of Education, Culture, Sports, Science and Technology of Japan. The authors have no conflicts of interest to declare.

\section{Author contributions}

Wurihan and Y.S. performed project planning, experimental work, data interpretation, and preparation of the manuscript. A.Y. and D.S. performed data analysis and collection. R.K and T.M. participated in data collection and planning.

\section{References}

Angker L, Swain MV, Kilpatrick N (2005) Characterising the micro-mechanical behaviour of the carious dentine of primary teeth using nano-indentation. J Biomech 38: 1535 1542.

Att W, Hori N, Takeuchi M, Ouyang J, Yang Y, Anpo M, Ogawa T (2009) Time-dependent degradation of titanium osteoconductivity: an implication of biological aging of implant materials. Biomaterials 30: 5352-5363.

Bonifacio A, Beleites C, Vittur F, Marsich E, Semeraro S, Paoletti S, Sergo V (2010) Chemical imaging of articular cartilage sections with Raman mapping, employing uniand multi-variate methods for data analysis. Analyst 135: 3193-3204.

Boyan BD, Hummert TW, Dean DD, Schwartz Z (1996) Role of material surfaces in regulating bone and cartilage cell response. Biomaterials 17: 137-146.

Butz F, Aita H, Wang CJ, Ogawa T (2006) Harder and stiffer bone osseointegrated to roughened titanium. J Dent Res 85: 560-565.

Chen D, Zhao M, Mundy GR (2004) Bone morphogenetic proteins. Growth Factors 22: 233-241.

Dehring KA, Crane NJ, Smukler AR, McHugh JB, Roessler BJ, Morris MD (2006) Identifying chemical changes in subchondral bone taken from murine knee joints using raman spectroscopy. Appl Spectrosc 60: 1134-1141.

Diebold U (2003) The surface science of titanium dioxide. Surface Science Reports 48: 53-229.

Dvir T, Timko BP, Kohane DS, Langer R (2011) Nanotechnological strategies for engineering complex tissues. Nat Nanotechnol 6: 13-22.

Field JS, Swain MV (1995) Determining the mechanical properties of small volumes of material from submicrometer spherical indentations. J Mater Res 10: 101-112.

Gong Y, Slee RB, Fukai N, Rawadi G, Roman-Roman S, Reginato AM, Wang H, Cundy T, Glorieux FH, Lev D, Zacharin M, Oexle K, Marcelino J, Suwairi W, Heeger S, Sabatakos G, Apte S, Adkins WN, Allgrove J, ArslanKirchner M, Batch JA, Beighton P, Black GCM, Boles RG, Boon LM, Borrone C, Brunner HG, Carle GF, Dallapiccola B, De Paepe A, Floege B, Halfhide ML, Hall B, Hennekam RC, Hirose T, Jans A, Jüppner H, Kim CA, Keppler-Noreuil K, Kohlschuetter A, LaCombe D, Lambert M, Lemyre E, Letteboer T, Peltonen L, Ramesar RS, Romanengo M,
Somer H, Steichen-Gersdorf E, Steinmann B, Sullivan B, Superti-Furga A, Swoboda W, Van den Boogaard MJ, Van Hul W, Vikkula M, Votruba M, Zabel B, Garcia T, Baron R, Olsen BR, Warman ML (2001) LDL receptorrelated protein 5 (LRP5) affects bone accrual and eye development. Cell 107: 513-523.

Gower LB (2008) Biomimetic model systems for investigating the amorphous precursor pathway and its role in biomineralization. Chem Rev, 108: 4551-4627.

Hanawa T, Kon M, Doi H, Ukai H, Murakami K, Hamanaka H, Asaoka K (1998) Amount of hydroxyl radical on calcium-ion-implanted titanium and point of zero charge of constituent oxide of the surface-modified layer. J Mater Sci Mater Med 9: 89-92.

He Z, Xu X, Song S, Xie L, Tu J, Chen J, Yan B (2008) A visible light-driven titanium dioxide photocatalyst codoped with lanthanum and iodine: An application in the degradation of oxalic acid. J Phys Chem C 42: 1643116437.

Iftikhar M, Hurtado P, Bais MV, Wigner N, Stephens DN, Gerstenfeld LC, Trackman PC (2011) Lysyl oxidaselike-2 (LOXL2) is a major isoform in chondrocytes and is critically required for differentiation. J Biol Chem 286: 909-918.

Iwai-Yoshida M, Shibata Y, Wurihan, Suzuki D, Fujisawa N, Tanimoto Y, Kamijo R, Maki K, Miyazaki T (2012) Antioxidant and osteogenic properties of anodically oxidized titanium. J Mech Behav Biomed Mater 13: 230236.

Jang IK, Tanaka R, Wurihan, Suzuki D, Shibata Y, Fujisawa N, Tanimoto Y, Ogura K, Kamijo R, Miyazaki $\mathrm{T}$ (2014) Nanomechanical properties and molecular structures of in vitro mineralized tissues on anodicallyoxidized titanium surfaces. Nanomedicine 10: 629-637.

Jones MI, McColl IR, Grant DM, Parker KG, Parker TL (2000) Protein adsorption and platelet attachment and activation, on TiN, TiC, and DLC coatings on titanium for cardiovascular applications. J Biomed Mater Res 52: 413-421.

Klinger A, Steinberg D, Kohavi D, Sela MN (1997) Mechanism of adsorption of human albumin to titanium in vitro. J Biomed Mater Res 36: 387-392.

Lin HY, Bumgardner JD (2004) Changes in surface composition of the Ti-6Al-4V implant alloy by cultured macrophage cells. Appl Surf Sci 225: 21-28.

McCafferty E, Wightman JP (1999) X-ray photoelectron spectroscopy sputter profile study of the native air-formed oxide film on titanium. Appl Surf Sci 143: 92-100.

McCarron EM (1990) Question of superoxide in La2CuO4+ $\delta$. Phys Rev B 41: 7238-7240.

Morita K, Miyamoto T, Fujita N, Kubota Y, Ito K, Takubo K, Miyamoto K, Ninomiya K, Suzuki T, Iwasaki R, Yagi M, Takaishi H, Toyama Y, Suda T (2007) Reactive oxygen species induce chondrocyte hypertrophy in endochondral ossification. J Exp Med 204: 1613-1623.

Mundy G, Garrett R, Harris S, Chan J, Chen D, Rossini G, Boyce B, Zhao M, Gutierrez G (1999) Stimulation of bone formation in vitro and in rodents by statins. Science 286: 1946-1949.

Ohtsuki C, Iida H, Hayakawa S, Osaka A (1997) Bioactivity of titanium treated with hydrogen peroxide 
solutions containing metal chlorides. J Biomed Mater Res 35: 39-47.

Okawa S, Watanabe K (2009) Chemical mechanical polishing of titanium with colloidal silica containing hydrogen peroxide - mirror polishing and surface properties. Dent Mater J 29: 68-74.

Oliver WC, Pharr GM (1992) Improved technique for determining hardness and elastic modulus using load and displacement sensing indentation experiments. J Mater Res 7: $1564-1580$.

Omori S, Shibata Y, Arimoto T, Igarashi T, Baba K, Miyazaki T (2009) Micro-organism and cell viability on antimicrobially modified titanium. J Dent Res 88: 957-962.

Ozawa S, Ogawa T, Iida K, Sukotjo C, Hasegawa H, Nishimura RD, Nishimura I (2002) Ovariectomy hinders the early stage of bone-implant integration: Histomorphometric, biomechanical, and molecular analyses. Bone 30: 137-143.

Park YJ, Song HJ, Kim I, Yang HS (2007) Surface characteristics and bioactivity of oxide film on titanium metal formed by thermal oxidation. J Mater Sci Mater Med 18: $565-575$.

Paschalis EP, Recker R, Dicarlo E, Doty SB, Atti E, Boskey A (2003) Distribution of Collagen Cross-Links in Normal Human Trabecular Bone. J Bone Miner Res 18: 1942-1946.

Rajagopal G, Maruthamuthu S, Mohanan S, Palaniswamy N (2006) Biocidal effects of photocatalytic semiconductor TiO2. Colloids Surf B Biointerfaces 51: 107-111.

Saruwatari L, Aita H, Butz F, Nakamura HK, Ouyang J, Yang Y, Chiou WA, Ogawa T (2005) Osteoblasts generate harder, stiffer, and more delamination-resistant mineralized tissue on titanium than on polystyrene, associated with distinct tissue micro- and ultrastructure. J Bone Miner Res 20: 2002-2016.

Shibata Y, He LH, Kataoka Y, Miyazaki T, Swain MV (2008) Micromechanical property recovery of human carious dentin achieved with colloidal nano- $\beta$-tricalcium phosphate. J Dent Res 87: 233-237.

Shibata Y, Hosaka M, Kawai H, Miyazaki T (2002) Glow Discharge Plasma Treatment of Titanium Plates Enhances Adhesion of Osteoblast-like Cells to the Plates Through the Integrin-Mediated Mechanism. Int J Oral Maxillofac Implants 17: 771-777.
Shibata Y, Suzuki D, Omori S, Tanaka R, Murakami A, Kataoka Y, Baba K, Kamijo R, Miyazaki T (2010) The characteristics of in vitro biological activity of titanium surfaces anodically oxidized in chloride solutions. Biomaterials 31: 8546-8555.

Shibata Y, Suzuki D, Wurihan, Yamada A, Maruyama N, Fujisawa N, Kamijo R, Miyazak iT (2013) Lysyl oxidase like-2 reinforces unsatisfactory ossification induced by bone morphogenetic protein-2: relating nanomechanical properties and molecular changes. Nanomedicine 9: 10361047.

Suda T, Jimi E, Nakamura I, Takahashi N (1997) Role of 1 $\alpha, 25$-dihydroxyvitamin D3 in osteoclast differentiation and function. Methods Enzymol 283: 223-235.

Takemoto S, Yamamoto T, Tsuru K, Hayakawa S, Osaka A, Takashima S (2004) Platelet adhesion on titanium oxide gels: Effect of surface oxidation. Biomaterials 25: 3485-3492.

Tengvall P, Lundström I, Sjöqvist L, Elwing H, Bjursten LM (1989) Titanium-hydrogen peroxide interaction: model studies of the influence of the inflammatory response on titanium implants. Biomaterials 10: 166-175.

Tizazu G, Adawi AM, Leggett G, Lidzey DG (2009) Photopatterning, etching, and derivatization of selfassembled monolayers of phosphonic acids on the native oxide of titanium. Langmuir 25: 10746-10753.

Vora SR, Palamakumbura AH, Mitsi M, Guo Y, Pischon N, Nugent MA, Trackman PC (2010) Lysyl oxidase propeptide inhibits FGF-2-induced signaling and proliferation of osteoblasts. J Biol Chem 285: 7384-7393.

Wang X, Shen X, Li X, Mauli Agrawal C (2002) Agerelated changes in the collagen network and toughness of bone. Bone 31: 1-7.

Zhao L, Wang H, Huo K, Cui L, Zhang W, Ni H, Zhang Y, Wu Z, Chu PK (2011) Antibacterial nano-structured titania coating incorporated with silver nanoparticles. Biomaterials 32: 5706-5716.

Editor's Note: All questions/comments by the reviewers were answered by text changes. There is hence no Discussion with Reviewers section. 